\title{
APROVEITAMENTO SUSTENTÁVEL DE BIOMASSA E DE RECURSOS NATURAIS NA INOVAÇÃo QUÍMICA
}

\author{
Fernando Galembeck*, César Augusto Sales Barbosa e Rafael Arromba de Sousa \\ Instituto de Química, Universidade Estadual de Campinas, CP 6154, 13083-970 Campinas - SP, Brasil
}

Recebido em 6/3/09; aceito em 18/3/09; publicado na web em 2/4/09

\begin{abstract}
SUSTAINABLE USE OF BIOMASS AND NATURAL RESOURCES FOR CHEMICAL INNOVATION. Increased production of biomass is currently the only immediately accessible alternative for large-scale carbon sequestration and it can produce large amounts of food, fuel and raw materials for the chemical industry that can in turn growingly replace oil as a source of organic building blocks and also of hydrogen and sulfur. Development of processes for biomass and abundant minerals transformation into chemical raw materials should now benefit from large inputs from nanotechnologies, biotechnologies, information and micro-reactor technologies. Success in R\&D\&Innovation along this line can yield new products and processes needed to perform desirable functions within a sustainable development paradigm.
\end{abstract}

Keywords: natural resources; biomass; climate change.

\section{INTRODUÇÃO}

No século 20, a indústria química tornou-se muito dependente do petróleo e a petroquímica assumiu um papel central, sendo em boa parte uma indústria de materiais. ${ }^{1}$ No início do século 21 , surgiram e estão crescendo pressões muito fortes para a substituição do petróleo: de um lado, a ameaça de escassez, a instabilidade de preços e a sua distribuição desuniforme, que tem causado até mesmo guerras; de outro lado, a necessidade de se estancar o atual processo de mudanças climáticas causadas pela atividade antrópica, especialmente pelas emissões de $\mathrm{CO}_{2}$, metano e óxidos de nitrogênio. Por outro lado, o atual contexto do desenvolvimento científico e tecnológico tem alguns elementos muito importantes: a emergência de novas tecnologias e a meta global de transição para uma economia sustentável, baseada em recursos renováveis. As tecnologias em questão são as nanotecnologias, biotecnologias e tecnologias de informação, que estão contribuindo para um avanço contínuo e acelerado na introdução de novos materiais funcionais e estruturais. $\mathrm{O}$ contexto da transição para a sustentabilidade teve como principal determinante a necessidade ou o interesse estratégico de se substituir petróleo por outras matérias-primas, mas outros elementos estão adquirindo importância crescente: a disponibilidade de água, a contaminação dos oceanos, a perda de qualidade e extensão de áreas agrícolas ao lado das necessidades crescentes de vastas populações que buscam melhores condições de vida. Uma estratégia para esta transição está em grande parte baseada no uso crescente de matérias-primas produzidas pelo agronegócio, criando o risco de uma competição pelo uso da terra para a produção de alimentos, energia e matérias-primas industriais. Entretanto, esta competição tem bases políticas e culturais, mais do que científicas ou tecnológicas. ${ }^{2}$

Este artigo não tem a pretensão de ser exaustivo ou mesmo abrangente, mas apresenta um diagnóstico da situação e formula objetivos e estratégias de uma ação coletiva, que produza um legado positivo para próximas gerações.

\section{AS NOVAS TECNOLOGIAS}

\section{Nanotecnologias}

Hoje, um número muito grande e sempre crescente de pesquisado-

*e-mail: fernagal@iqm.unicamp.br res e de empresários está atento às nanotecnologias em todo o mundo. Está claro para as pessoas mais lúcidas que não se trata simplesmente de uma nova tecnologia, e também que esta não será a base de uma indústria específica, mas sim que se trata de um conjunto de conceitos, conhecimentos e de ferramentas experimentais que permite um novo nível de domínio da matéria nas condições ambientes, criando novas estruturas organizadas a partir da escala molecular, dotadas de propriedades microscópicas e macroscópicas que as tornem capazes de desempenharem funções necessárias à melhoria da qualidade de vida humana. Em alguns casos, tais funções são hoje desempenhadas por substâncias químicas, materiais ou dispositivos já existentes, mas que apresentam limitações de desempenho. Em outros casos, talvez os mais interessantes, as funções serão totalmente novas.

Situadas entre as principais áreas de investigação, integrando a química e a ciência dos materiais, a física e a biologia para criar novas e inéditas propriedades que possam ser exploradas, nanotecnologias atendem a muitas necessidades de mercado, como as de materiais poliméricos de alto desempenho, têxteis avançados, materiais eletrônicos e fotônicos, biomédicos, materiais metálicos e poliméricos de alto desempenho para as indústrias de transportes, habitação, alimentos, entretenimento e produtos ao consumidor.

As nanotecnologias são pervasivas e já se fazem presentes em produtos e processos de qualquer setor das indústrias de transformação, bem como em muitas etapas de cadeias produtivas do agronegócio e nos setores mineral e de serviços. Esta é uma avaliação positiva, mas que não repete os infinitos exageros e erros que têm sido veiculados em livros e na mídia, sobre a nanotecnologia.

No caso presente, das nanotecnologias voltadas para o aproveitamento de matérias-primas naturais e a produção química e de materiais avançados em uma perspectiva brasileira, é necessário considerar possibilidades e oportunidades, optando por estabelecer metas ambiciosas mas viáveis, que se transformem em resultados importantes e que contribuam para a economia e para a qualidade de vida da população. Nesse sentido, as nanotecnologias podem trazer grandes mudanças no perfil das atividades científicas e tecnológicas no Brasil, fazendo convergir ainda mais as atividades acadêmicas e as atividades econômicas, que no setor químico mostram uma forte interação.

As idéias e ferramentas nanotecnológicas estão criando grandes sucessos ao transformarem substâncias simples e matérias-primas triviais em novos materiais com propriedades extremamente atraentes. 
Isto cria oportunidades excelentes para uma vultosa agregação de valor aos recursos naturais de todos os tipos.

Além disso, os materiais nanotecnológicos estão quebrando numerosos paradigmas das relações estrutura-função de materiais, seja produzindo combinações de propriedades que violam conceitos bem estabelecidos, seja apresentando-se como metamateriais, cujas propriedades dependem da organização nanométrica e micrométrica, mais do que das suas propriedades intrínsecas. ${ }^{3}$

Estas idéias estão expressas, por exemplo, em uma excelente análise do papel das nanotecnologias na indústria química que foi publicada por um grupo da DuPont, e está resenhada a seguir. ${ }^{4}$ Os autores começam lembrando que a indústria química é em grande parte madura e que muitos dos seus produtos são commodities baseadas em tecnologias bem estabelecidas. Portanto, novos produtos e novas oportunidades de mercado virão, provavelmente, das especialidades químicas e de novas funcionalidades obtidas graças às novas tecnologias de processo e às novas metodologias de controle de microestruturas. Estes autores confirmam que, tanto quanto a estrutura molecular, a microestrutura de um material tem um papel determinante das suas propriedades e definem nanotecnologia como sendo a manipulação controlada de nanomateriais com pelo menos uma dimensão inferior a $100 \mathrm{~nm}$. Para eles, o controle de estruturas nos níveis micro e nano é essencial para o surgimento de novas descobertas. Finalmente, os autores propõem um roadmap ou mapa do caminho da inovação nanotecnológica, que identifique as interdependências entre o desenvolvimento dos nanoblocos, o design de produtos, o projeto de processos e a integração da cadeia de valores. O modelo de P\&D que eles sugerem é uma combinação de demandas de mercado e ofertas tecnológicas (market pull e technology push), para que as vantagens nanotecnológicas sejam rapidamente traduzidas em benefícios ao consumidor.

Um outro esforço, envolvendo um grande número de empresas, entidades e pessoas, foi feito no âmbito da "Vision 2020", 5 um processo colaborativo liderado pela indústria, para acelerar a inovação e o desenvolvimento tecnológico através da mobilização de recursos materiais e humanos. Um resumo das motivações e objetivos do grupo foi divulgado nos seguintes termos: "Nanotechnology is an important new research area. The chemical industry may be the only industry with $R \& D$ capabilities and expertise to commercialize nanotechnology advances.... Consequently, the chemical industry should have a voice in the selection of $R \& D$ topics pursued by the Federal government. The chemical industry, along with the electronics industry, are the two industries that have the most to benefit from guiding the nanotechnology $R \& D$ funding. Vision2020 is currently working to improve communication with nanotechnology funding agencies to make sure they are focusing on areas relevant to the industry. The systematic research in nanotechnology is just beginning. The infrastructure is forming. The integration of new phenomena into macroscopic systems is not yet being emphasized." Esse grupo produziu um documento exemplar, o "Nanomaterials and the Chemical Industry R\&D Roadmap Workshop: Preliminary Results", de 2002, que pode ser obtido da Internet. ${ }^{6}$

Os fatos econômicos, desde 2002, confirmam as predições feitas no documento referido: grande parte dos novos produtos nanotecnológicos tem saído das empresas do setor químico: são os materiais poliméricos, os novos cosméticos, embalagens revolucionárias e numerosos outros produtos que estão revolucionando a vida diária e criando plataformas radicalmente novas para a produção industrial.

No Brasil, esta situação é ainda mais claramente definida, não apenas pela força da indústria química como também pela fraqueza da indústria de semicondutores e de equipamentos para as tecnologias da informação. ${ }^{7}$ Graças a esta situação, os desenvolvimentos tecnológicos nesta área, no Brasil, estão quase completamente confinados ao setor químico. ${ }^{8}$

\section{Biotecnologias}

Os impactos da biotecnologia na produção de materiais são tão amplos e diversificados quanto os das nanotecnologias, seja diretamente, seja através da produção de matérias-primas para a produção de materiais. Para efeito de discussão, as biotecnologias serão classificadas em dois grupos: "de processos, inclusive fermentativos" e "genômicas", reconhecendo que há uma extensa interface, entre os dois.

O primeiro grupo é representado, por exemplo, pela produção de álcool etílico e outros produtos de biomassa, usando processos fermentativos ou não. Um caso importante é o das empresas de agronegócio que se tornaram produtoras químicas, como a Archer Daniels Midland (ADM) e Cargill, nos Estados Unidos, a Ajinomoto japonesa e outras. Nos últimos anos, estas empresas deslocaram o etanol petroquímico para fora do mercado global, processo este que no Brasil ocorreu desde sempre. Seus produtos competem hoje com vários petroquímicos: agentes de coalescência da Eastman, astaxantina da BASF e DSM, propilenoglicol e etilenoglicol da Dow, Lyondell e outras, termoplásticos como os poli(hidroxialcanoatos). Em 2006, a Cargill tornou-se fornecedora de polióis (que são tradicionalmente derivados de petróleo) produzidos a partir de óleos vegetais, para a indústria de poliuretanos. A Ajinomoto tem uma importante operação no Brasil, ${ }^{9}$ produzindo 72 mil toneladas de lisina por ano, em Valparaiso, SP, e mais 60 mil toneladas em Pederneiras, SP, usando matérias-primas derivadas da cana-de-açúcar.

Quanto às tecnologias genômicas, as possibilidades são absolutamente fantásticas e podem ser exemplificadas com o recente esforço de fabricação de fibras poliméricas baseadas na inserção de genes de aranhas em cabras, vacas ou outras espécies. ${ }^{10}$ Nesse caso concreto, o leite de cabras transgênicas produz proteínas de teias de aranhas, que são reconhecidamente as fibras mais resistentes existentes em todo o mundo. O sucesso em um projeto deste tipo significa que um rebanho de cabras, associado a uma usina de processamento do leite e extração de proteína de fibras, pode vir a competir com os produtores de fibras de aramida, de carbono e outras fibras de alto desempenho.

\section{Tecnologias da informação (TIs)}

As tecnologias da informação têm permitido um grande aumento no acesso à informação científica e tecnológica. Poucos anos atrás, o discurso de muitos pesquisadores costumava incluir longas lamentações sobre a impossibilidade de uma pessoa, por mais bem preparada que fosse, manter um efetivo acompanhamento da literatura científica e tecnológica. Essa situação mudou radicalmente. Um exemplo dramático é o de patentes: há duas décadas, um brasileiro que precisasse fazer buscas sobre patentes tinha de recorrer ao Chemical Abstracts, que lhe fornecia resumos, ou à revista do INPI, para obter informação sobre patentes depositadas no Brasil. Para obter documentos completos, a solução mais viável era dirigir-se ao banco de patentes do INPI, no Rio de Janeiro, o que exigia um esforço físico e financeiro significativo.

Hoje, as buscas podem ser efetuadas usando algum dos vários bancos e ferramentas de recuperação de informação. Qualquer pessoa que tenha acesso à internet pode fazer buscas no USPTO e na base européia Espacenet, recuperando documentos completos, em minutos. A internet apresenta um bom número de endereços de acesso livre através do Google e outras ferramentas de busca. Portanto, hoje em dia é muito mais fácil obter informação sobre patentes do que sobre artigos científicos.

Outros impactos das TI's sobre a inovação se fazem sentir nos laboratórios, desde os robôs que realizam experimentos até as múltiplas técnicas de simulação e modelagem, de planejamento experimental, análise de resultados e reconhecimento de padrões. 


\section{Tecnologias de microrreatores}

O trecho seguinte é uma transcrição de texto de um dos autores, apresentado em um recente evento sobre química verde:" "Progress in microreactors is being very fast and this creates an important trend for the chemical industry. ${ }^{12}$ This is a very recent development as observed by noting that the oldest reference in a 2002 paper in the IUPAC Pure and Applied Chemistry journal dates from 1999. A leading research place in this area is Batelle Pacific Northwestern National Laboratory - PNNL (Richland, WA). Microtechnology was a key tool in the development of the micro chemical and thermal systems (MicroCats) being developed at PNNL and according to PNNL's David Brenchley, "just as rapid advances in microelectronics have revolutionized computers, appliances, communication systems and many other devices, PNNL's efforts in creating MicroCats will revolutionize heat exchangers, heat pumps, combustors, gas absorbers, solvent extractors, fuel processors and many other devices." These devices can be mass-produced, says PNNL, using it's patented "sheet architecture" to yield efficient, compact and cost-effective systems. The laboratories have developed their own microfabrication techniques, including conventional machining, photolithography, non-reactive ion etching and chemical etching, and photo-ablation with excimer lasers. The microdevices have been made in copper, aluminum, stainless steel, high-temperature alloys, plastics and ceramics.

In Japan, AIST announced ${ }^{13}$ that "We have developed a microreactor for the production of specialty chemicals; using this microreactor, we have realized small space, low environmental load, rapid and highly selective chemical processes; the microreactor enables rapid production of small amounts of a variety of items, contributing to strengthening the competitive power of the fine chemical industries."

A detailed analysis by researchers from the Lonza company on the application of microreactors to fine chemicals industry shows that it is too early to know if microreactors will revolutionize the production of fine chemicals and pharmaceuticals. It calls for the development of microreactors capable of handling solids and on yield improvements to justify higher investment costs. ${ }^{14}$ Other chemical and equipment companies have made open presentations of their results, like Rhodia ${ }^{15}$ and Siemens. ${ }^{16}$

Work to solve solids handling problems is underway e.g. in TNO according to the following release: "A good example of an application that can benefit from the features of the Helix reactor is crystallisation. In continuous precipitation it is difficult to generate particles with a narrow size distribution and to control the morphology...the enhanced mixing properties of the Helix reactor will result in particles having more controlled properties. For a model system $\left(\mathrm{CaCO}_{3}\right)$ it was found that changes in size and shape occurred in the Helix-reactor compared to a stirred tank reactor and to a straight tube (see figure below). Coating of particles is another possible application. ${ }^{17}$ ",

The risk of decentralization of the chemical production of warfare chemicals has also been considered by Tuan Nguyen, from the Lawrence Livermore National Laboratory: "Although the full chemical synthesis potential of microreactors is not yet clear, several lethal chemicals - hydrogen cyanide, phosgene and methyl isocyanatehave already been produced using this system... In China, nitroglycerine has recently been produced using microprocess technology at a maximum rate of 10 kilograms per hour. ${ }^{18}$ ",

Even though microreactors are often associated to small-scale production of expensive or high-risk chemicals, the PNNL strategy has given a lot of attention to large-scale reactions. The USPTO has already issued 20 patents to Anna Tonkovich and other inventors, with the keyworks microchannel or microreactor."
Esta área tem recebido atenção no Brasil, embora talvez não na escala desejada. Um indicador da atenção e capacitação brasileiras na área é a existência de um projeto de uma planta-piloto do processo Fischer-Tropsch de produção de combustíveis, que está sendo executado por uma equipe do Cenpes (Petrobrás) com um orçamento de vinte milhões de dólares. ${ }^{19}$

\section{A substituição do petróleo por matérias-primas naturais}

Um fenômeno importante do início do século 21 é a transição para uma atividade industrial menos dependente do petróleo, no sentido oposto ao que foi observado ao longo do século 20.

No início do século 20, os motores a explosão eram uma novidade, o automóvel e o avião estavam sendo inventados graças à disponibilidade de uma recente invenção, o motor a gasolina. A produção de petróleo era pequena e o gás natural despertava pouco interesse. As matérias-primas da indústria química orgânica eram de origem vegetal ou animal, além do alcatrão obtido na fabricação de coque siderúrgico. O carvão era a fonte de gás combustível usado em iluminação, em aquecimento e nas cozinhas das grandes cidades, além de produzir coque e alcatrão.

Ao longo do século 20, o petróleo tornou-se também uma importante fonte de materiais e a indústria petroquímica expandiu-se enormemente, tornando-se a fonte de borrachas e de plásticos que vêm substituindo metais, cerâmicas, papéis e outros materiais, em grande escala. Essa expansão foi viabilizada pelas tecnologias e logística de exploração, refino e distribuição do petróleo. Por outro lado, ela mudou a própria face da indústria química, que deixou de ser uma indústria de corantes, medicamentos e fertilizantes passando a ser, em grande parte, uma indústria de materiais.

A disponibilidade e o baixo preço do petróleo criaram até mesmo, em um certo momento, a ilusão de que ele poderia ser uma alternativa para a produção de alimentos. ${ }^{20}$ Antes do primeiro choque do petróleo chegou a existir um esforço importante de C\&T para o desenvolvimento de processos fermentativos geradores de produtos que poderiam ser usados na alimentação animal e humana, a partir do petróleo. A lembrança desse episódio é necessária como registro da enormidade de diferença nas perspectivas da humanidade e especialmente dos países mais desenvolvidos, em um curto lapso de 40 anos, quanto à produção de energia, alimentos e materiais.

Mesmo assim, o petróleo tem tido um papel fundamental na produção de alimentos, uma vez que é a principal fonte do hidrogênio hoje disponível no mundo e usado no processo Haber-Bosch para produzir amônia e fertilizantes nitrogenados. Neste processo são consumidos quase $2 \%$ de toda a energia produzida no mundo, mas fornecendo a cerca de um terço da humanidade as proteínas da sua alimentação. ${ }^{21}$

No fim do século 20, tornou-se clara a necessidade de alternativas ao petróleo, por três razões: a perspectiva da escassez, a sua concentração em algumas poucas regiões do mundo e a sua contribuição para as mudanças climáticas globais. As duas primeiras causas têm provocado uma rápida escalada de preços que está viabilizando economicamente outras fontes e vetores de energia, muitas delas conhecidas há muito tempo, mas economicamente inviáveis face às enormes vantagens e conveniências oferecidas pelos combustíveis líquidos e gasosos derivados do petróleo e gás natural.

$\mathrm{Na}$ falta de alternativas, ocorrem fenômenos importantíssimos de alcance global. Por exemplo: a indústria química dos Estados Unidos, que há muitas décadas tem a liderança global, vem assistindo a um processo de esvaziamento. O mais claro indicador desse processo é o surgimento de um deficit no balanço de pagamentos do setor químico norte-americano, que tem um importante efeito multiplicativo por reduzir a competitividade de vários outros setores industriais. ${ }^{22}$ 
Uma causa importante desse processo é o preço elevado do gás natural nos Estados Unidos: tratando-se hoje do principal insumo dessa indústria, ele reduz a sua competitividade face aos outros países industrializados.

Em uma perspectiva da metade do século 20, a substituição do petróleo poderia perfeitamente ser feita com derivados de carvão, gás natural, xisto e areias betuminosas, especialmente considerando-se os grandes estoques de metano na forma de clatratos, em grandes profundidades oceânicas. Isso poderá ocorrer, em alguns países que tenham vantagens comparativas para o uso desses recursos minerais. No Brasil, essa não é uma hipótese muito forte dadas as conhecidas deficiências do carvão mineral brasileiro e os vários problemas ambientais já revelados na exploração do xisto betuminoso, muito abundante na Bacia do Paraná.

O carvão, gás e xisto certamente terão um papel nos cenários futuros de energia e de suprimentos de matérias-primas para a produção de materiais, mas este será modulado pelas fortes pressões ambientais contrárias ao seu uso, em todo o mundo. De fato, já estão surgindo propostas radicais, como a feita por John Tidwell em um recente evento sobre mudanças climáticas, segundo as quais o que realmente tem de ser feito com os combustíveis fósseis é deixá-los em repouso, por mais alguns milhões de anos para evitar o agravamento das mudanças climáticas. ${ }^{23}$ Portanto, urge encontrar novas fontes de matérias-primas para a produção química e de materiais.

Neste cenário, as matérias-primas naturais de origem vegetal ou animal, de fontes renováveis, adquirem uma importância especial ao lado das matérias-primas minerais muito abundantes e que se prestem à produção química e de materiais.

Por isto mesmo, surge frequentemente o seguinte argumento: "o uso dos materiais derivados do petróleo, como os plásticos, deve ser desencorajado em um cenário de escassez ou de redução do uso do petróleo". Este argumento ignora que a produção e uso de metais e cerâmicas envolve gastos totais de petróleo muito superiores aos feitos na produção de plásticos, devido à sua elevada densidade e às altas temperaturas de processamento.$^{24}$ Além disso, ignora que o polietileno, polibutadieno e outros produtos petroquímicos já foram produzidos com matérias-primas de fonte vegetal e renovável e estão voltando a sê-lo.

\section{Matérias-primas vegetais e sustentabilidade}

O processo de substituição do petróleo como fonte principal de matérias-primas da indústria petroquímica já começou. Nos Estados Unidos, o etanol petroquímico já não é competitivo e já há outros exemplos de substituição, como o caso recente da produção de propilenoglicol, em uma joint-venture da Dow e Cargill. ${ }^{25}$ No Brasil, há exemplos históricos de produção de polímeros a partir do álcool e desde 2007 estão em curso iniciativas importantes, por exemplo a da Oxiteno, em uma planta oleoquímica e da Braskem, na produção de polietileno. Portanto, não se trata mais de uma perspectiva e sim de uma realidade pujante e de uma imensa oportunidade para o Brasil. Entretanto, não é possível ignorar que este, como qualquer outro processo de crescimento, pode gerar problemas.

Em meados de 2008, os preços do etanol produzido nos estados de São Paulo, Paraná, Mato Grosso do Sul, Goiás e no Triângulo Mineiro lhe garantiam competitividade como insumo da indústria petroquímica face ao petróleo.

Até aqui, este processo tem sido conduzido simplesmente pelas forças de mercado, com poucas intervenções do governo brasileiro. No passado, o Proálcool viabilizou o etanol combustível, a um custo estimado em 10 bilhões de dólares. O Presidente da República tem feito uma defesa forte, fundamentada e competente do etanol brasileiro, mas não existe hoje, no Brasil, um plano estratégico que considere as três dimensões do seu uso: alimentos, energia e materiais. O Plano de Ação que tem sido anunciado pelo MCT praticamente ignora esse assunto, embora ele diga respeito, diretamente, aos principais setores da economia brasileira. ${ }^{26} \mathrm{~A}$ existência e execução competente de um tal plano poderiam levar o Brasil a uma posição privilegiada como produtor alcoolquímico de um sem-número de produtos de uso industrial, por via fermentativa ou usando processos derivados da atual petroquímica. Situações análogas deveriam também ser criadas com relação à oleoquímica, lignoquímica e outros subssetores.

Por outro lado, a falta de planejamento já está criando inúmeros conflitos, até mesmo no nível de legislação municipal de uso da terra e prejudicará, em primeiro lugar, a produção de alimentos, seguida pela de matérias-primas. Os prejuízos à produção destas serão devidos, principalmente, à falta de segurança dos investidores para o projeto, construção e operação de unidades de produção alcoolquímica, devido à dimensão dos mesmos e aos longos prazos de amortização.

Para resolver problemas deste tipo, o planejamento poderá potencializar sinergias já existentes e outras que poderão ser criadas ou descobertas, contribuindo para aumentos expressivos na produção de alimentos, energia e materiais a partir da cana-de-açúcar, de oleaginosas, madeira e outros produtos vegetais e animais.

\section{Matérias-primas minerais e sustentabilidade}

Muitas matérias-primas minerais de baixo valor unitário têm amplo uso industrial, recebendo hoje redobrada atenção devido à sua importância na geração de produtos nanotecnológicos.

Argilas, outros silicatos, carbonato de cálcio e sílica são usadas em uma ampla gama de produtos industriais, em quantidades muito elevadas.

\section{Rejeitos de produção mineral e do agronegócio}

A indústria química é uma importante fonte de matérias-primas para as indústrias de materiais e ela, por sua vez, tem sido fortemente baseada na disponibilidade de matérias-primas abundantes, baratas e frequentemente indesejáveis.

Por outro lado, a produção mineral e o agronegócio geram grandes quantidades de resíduos que assumem características de problemas ambientais. Esforços de pesquisa e desenvolvimento bem focalizados podem perfeitamente transformar estes problemas ambientais em soluções para o suprimento de matérias-primas para materiais.

O exemplo histórico mais importante é o do próprio petróleo. Ainda no século XIX, a ocorrência de petróleo em propriedades rurais no Oklahoma era uma desvantagem, devido à sua vinculação com a baixa produtividade agrícola da terra. ${ }^{27}$ No século XX, o petróleo tornou-se uma das principais matérias-primas na produção de materiais, em todo o mundo.

Um exemplo brasileiro recente de transformação de um dejeto em matéria-prima é o da vinhaça resultante da produção de álcool. Despejada sem tratamento, a vinhaça sofre um processo de putrefação que produz uma repulsiva poluição atmosférica. Despejada em rios, produz um grande aumento na demanda de oxigênio de cursos de água. Por essa razão, a vinhaça foi o agente causador de numerosos episódios de contaminação ambiental, até ser desenvolvida uma tecnologia do seu aproveitamento na reposição de nutrientes do solo, especialmente fósforo $(\mathrm{P})$ e potássio $(\mathrm{K}){ }^{28}$

A atividade industrial e agrícola sempre gera resíduos abundantes, em muitos setores. Um exemplo do setor agrícola é a casca do arroz, que já tem sido explorada como fonte de energia (em combustão) e de sílica microparticulada, abundante nas cinzas resultantes da sua queima, que é hoje um importante aditivo de cimentos Portland. ${ }^{29}$ 
Entretanto, há volumosos resíduos, gerados ao longo de muitas décadas, nas indústrias de carvão (piritas), fertilizantes (sílica e fosfogesso), xisto betuminoso (a fração mineral), entre outras, que hoje são problemas para os geradores de resíduos, seus vizinhos e as agências de controle ambiental. Urge encontrar aplicações, o que depende de um trabalho conjunto de pesquisadores, engenheiros e de profissionais que conheçam bem diferentes mercados e sejam capazes de, conjuntamente, formularem e executarem projetos de aplicação.

Um foco prioritário destes projetos seria o aproveitamento de potássio. Esse elemento é essencial à produção agrícola e o cloreto de potássio é o principal item da pauta de importações do setor químico no Brasil, montando em 2005 a cerca de 1 bilhão de dólares. ${ }^{30}$ Portanto, trata-se de um item realmente importante para a economia nacional. Por outro lado, dejetos humanos incluem diariamente, cerca de $40 \mathrm{mg}$ de potássio, o que significa que os quase 200 milhões de brasileiros dejetam diariamente 8 toneladas de potássio. A quantidade equivalente de cloreto de potássio, em base anual, monta a mais de 5 mil toneladas. A esse número devem se acrescidos os dejetos de gado, frango e outras espécies produzidas em larga escala, no Brasil. Portanto, o manejo de resíduos humanos e animais pode ser fonte de uma matéria-prima que hoje onera fortemente o comércio exterior brasileiro - e é essencial para a produção agrícola, portanto para a produção de materiais.

Projetos de aplicação promissores permitiram transformar o que, até recentemente, era considerado como rejeito de atividade industrial e um passivo ambiental, em fonte de matéria-prima para outros setores da indústria e, portanto, com valor econômico agregado.

A indústria siderúrgica, responsável pela produção do aço, gera, em média, 0,42 toneladas de rejeito por tonelada de aço produzida. ${ }^{31}$ Cerca de $80 \%$ deste subproduto é composto pela escória, material constituído principalmente por calcário, sílica e óxido de ferro. Em 2006, a siderurgia brasileira gerou cerca de 10 milhões de toneladas de escória. ${ }^{32}$ Até o fim da década de 90, a escória tinha como destino único aterros industriais ou mesmo o abandono no meio ambiente, provocando contaminação do solo e da água.

O esforço conjunto de profissionais do setor siderúrgico e do setor acadêmico, com o apoio de agências de fomento, permitiu uma mudança de paradigma para o destino da escória, que é hoje totalmente reaproveitada, sendo utilizada, principalmente, como matéria-prima para a produção de cimento e fibro-cimento. O reaproveitamento da escória agrega um dividendo ambiental, pois reduz o consumo de recursos minerais não renováveis, como o calcário e a argila usados na produção do cimento convencional.

A produção de alumínio é outra atividade industrial que gera um grande volume de rejeitos. Existe um elevado reaproveitamento, através da reciclagem, do alumínio produzido no Brasil. ${ }^{33}$ Este atinge $36,7 \%$ (relação entre sucata de alumínio recuperada e consumo doméstico), mais que a média mundial de $29,3 \%$. Entretanto, o principal rejeito da produção de alumina (matéria-prima para produção de alumínio), conhecido como lama vermelha, ainda é destinado a depósitos de resíduos conhecidos como "lagos de disposição". A lama vermelha é constituída por óxidos insolúveis (principalmente ferro, silício e alumínio) dispersos em um meio altamente alcalino.

A produção de alumina gera, em média, 0,9 tonelada de lama vermelha por tonelada de alumina produzida (o volume de rejeito gerado depende da qualidade da bauxita, minério utilizado para a produção de alumina) ${ }^{34}$ Considerando que a produção brasileira de alumínio em 2005 foi de aproximadamente 5 milhões de toneladas, foram geradas 4,5 milhões de toneladas de lama vermelha. Além do enorme passivo ambiental, seu descarte custa à indústria de alumínio cerca de US $\$ 3$ por tonelada de alumina produzida, ${ }^{35}$ custo econômico significativo, considerando o volume de rejeito gerado.
Há iniciativas interessantes para o reaproveitamento do material contido na lama vermelha: ${ }^{36}$ utilização como matéria-prima para produção de materiais para a construção civil (cimentos especiais, revestimentos cerâmicos, tijolos e telhas), como corretivo para solos ácidos ou pobres em ferro e como adsorvente para remoção, seja de metais pesados, seja de fósforo (fosfatos), nitrogênio (amônia e nitratos) ou ainda de corantes, no tratamento de solos contaminados, efluentes líquidos e esgoto doméstico.

Apesar das diferentes possibilidades do reaproveitamento da lama vermelha e mesmo a comercialização de alguns produtos derivados do seu uso, nenhuma das aplicações se mostrou tecnológica e economicamente consolidada para o pleno reaproveitamento deste rejeito. ${ }^{37}$ Este fato é retratado nas publicações do setor, ${ }^{33,34,38,39}$ que não reportam qualquer reaproveitamento da lama vermelha, mas apenas o seu descarte em lagoas de disposição. Portanto, urge a necessidade de iniciativas inovadoras, mudando a situação atual.

Recentemente a Alcoa, maior produtora mundial de alumínio, anunciou uma solução relativamente simples, porém inovadora: a utilização da lama vermelha para captação de gás carbônico. ${ }^{40}$ Este procedimento permite, além da neutralização do rejeito, a redução de emissões de gás carbônico no ciclo de produção do alumínio. A implementação desta tecnologia teve início em uma unidade industrial na Austrália. A Alcoa pretende capturar, utilizando-se desta nova tecnologia, cerca de 300 mil toneladas de gás carbônico por ano, o equivalente à emissão total de suas unidades na Austrália. No Brasil, onde abundam solos ácidos e extensamente lixiviados, esta estratégia pode ser associada à produção de corretivos de solo, reduzindo o uso de calcário que é um emissor de $\mathrm{CO}_{2}$.

Os rejeitos do agronegócio, sejam estes resíduos vegetais ou animais, também oferecem oportunidades de reaproveitamento. Estes rejeitos são gerados em grandes volumes, em todas as atividades agrícolas no Brasil. ${ }^{41}$ Alguns exemplos estão na Tabela 1.

Parte dos rejeitos do agronegócio é reaproveitada, principalmente como ração animal, na produção de fertilizantes orgânicos e como biomassa para geração de energia. ${ }^{42} \mathrm{O}$ caso do bagaço de cana é exemplar: ele é usado como fonte de energia nas usinas de álcool (que no passado queimavam óleo combustível ou lenha) e o excedente dessa energia é vendido como eletricidade. A capacidade geradora das usinas fornecedoras da rede elétrica chegou a 1,5 Gw em 2008 e poderá atingir $10 \mathrm{Gw}$ em poucos anos, o que equivale a mais do total de energia que o Brasil importa do Paraguai, gerada em Itaipu. Porém, estima-se que não sejam aproveitados, no Brasil, mais de 200 milhões de toneladas de rejeitos da atividade agroindustrial, uma quantidade superior à produção brasileira de grãos.

Tabela 1. Alguns produtos agrícolas e seus resíduos no Brasil, em 2004

\begin{tabular}{lcc}
\hline Matéria-prima/resíduo & $\begin{array}{c}\text { Produção } \\
\text { agrícola (t) }\end{array}$ & $\begin{array}{c}\text { Produção total } \\
\text { de resíduos (t) }\end{array}$ \\
\hline Cana (bagaço) & 396.012 .158 & 59.401 .824 \\
Soja (grãos vs. restos de cultura) & 51.919 .440 & 80.746 .839 \\
Milho (palha e sabugo) & 48.327 .323 & 64.028 .870 \\
Mandioca (rama) & 21.961 .082 & 6.542 .206 \\
Arroz (casca) & 10.334 .603 & 2.937 .094 \\
Café (casca) & 12.454 .470 & 1.662 .658 \\
\hline
\end{tabular}

Na geração de energia, o rejeito é utilizado in natura, diretamente como combustível, sendo queimado em fornos e caldeiras. Processos mais inovadores utilizam-se do rejeito como matéria-prima na digestão anaeróbia para a produção de metano. $\mathrm{O}$ recente esforço 
governamental para a produção de biodiesel em larga escala ${ }^{43}$ vem influenciando fortemente o destino e os preços de gordura animal residual, como o sebo bovino, suíno e de aves.

O biodiesel é produzido a partir de óleos vegetais, oriundos de plantas oleaginosas (soja, girassol, mamona, entre outras) ou de gorduras de origem animal. A aplicação usual do sebo tem sido a indústria de saboaria, apesar de utilizações nas indústrias de cosméticos, ração animal e indústria química.

Recentemente, porém, o sebo tem sido usado diretamente como combustível em caldeiras. ${ }^{44}$ Apesar de ter um poder calorífico $10 \%$ inferior ao do óleo combustível, ocorre uma redução de cerca de $8 \%$ nos custos de operação das caldeiras, por conta de diferenças de taxação de impostos entre o sebo e o óleo combustível, além da redução da poluição, com grande redução na emissão de material particulado. Tratando-se de um combustível oxigenado, o sebo queima de maneira mais completa que o óleo combustível, produzindo menos fuligem.

Além disso, o sebo bovino também tem sido utilizado na produção de biodiesel por parte dos frigoríficos. A Fertibom Indústrias Ltda iniciou suas operações em janeiro de $2006^{45}$ e o Grupo Bertin inaugurou sua usina em Lins em agosto do corrente ano, com capacidade de 110 milhões de litros de biodiesel por ano, produzidos em regime contínuo. ${ }^{46} \mathrm{O}$ aumento da demanda pelo sebo tem se refletido no seu preço de mercado, com aumento muito superior àquele registrado para a carne bovina. A nova forma de reaproveitamento do sebo pressionou sua cotação, fazendo o preço dobrar em apenas um ano: passou de $\mathrm{R} \$$ $550,00 / \mathrm{t}$ (fevereiro/2006) para R $\$ 1.100,00 / \mathrm{t}$ (janeiro/2007) ${ }^{47}$ sendo ainda vantajoso quando comparado com a cotação do óleo de soja ( $\$$ \$ 1.667,50/t; janeiro/2007). ${ }^{48}$ A produção de biodiesel no Brasil teve, em 2008, duas matérias-primas principais: o óleo de soja (80\%) e o sebo bovino $(17 \%) .^{49}$

A utilização de processos biotecnológicos é outra possível estratégia para o reaproveitamento de rejeitos da agroindústria. ${ }^{50,51}$ Dentre as técnicas de bioprocessamento, destacam-se os processos fermentativos, largamente utilizados para a obtenção dos mais diferentes produtos. ${ }^{52}$
O processamento biotecnológico através da fermentação em estado sólido ocorre através da ação de micro-organismos (bactérias) sobre os componentes do rejeito sólido (sem presença de água livre), utilizando-os como nutrientes para o crescimento microbiano. ${ }^{53} \mathrm{~A}$ escolha adequada do micro-organismo permite a bioconversão do rejeito em substâncias com valor maior agregado, utilizadas por indústrias de diferentes setores como, por exemplo, enzimas, hormônios, ácidos orgânicos, aromas e pigmentos, entre outros. A Tabela 2 apresenta algumas possibilidades de reaproveitamento de rejeitos industriais, juntamente com os micro-organismos utilizados e a substância obtida através do processo fermentativo.

A lista reproduzida acima não é exaustiva e apenas ilustra as muitas possibilidades existentes. ${ }^{54}$

O desenvolvimento da fermentação em estado sólido para a aplicação em escala comercial ainda é incipiente; o Japão é o país que explora mais ativamente esta tecnologia, devido à extensa utilização de processos fermentativos em estado sólido, principalmente para a preparação de 'shoyo' (processo Koji). Biorreatores são comercializados para este fim, além de serem adaptados para a produção de outras substâncias de interesse industrial: cerca de 20\% do ácido cítrico produzido no Japão é obtido através de fermentação do farelo de trigo em estado sólido A Índia também possui know-how no desenvolvimento de biorreatores comerciais para processos fermentativos em estado sólido. ${ }^{55}$

O Brasil possui grupos de pesquisas ativos na área com uma produção significatica, porém não há registro de utilização de processos fermentativos em estado sólido em nível comercial. Esta situação é resultado do pouco know-how relacionado à engenharia do processo. Porém, com o contínuo desenvolvimento tecnológico, ${ }^{56,57}$ o processo pode difundir-se, tornando-se economicamente atrativo e intensificando cadeias produtivas no Brasil.

\section{Análise e caracterização}

Toda a atividade química depende muito de trabalho analítico e o desenvolvimento de produtos e processos requer um intenso trabalho

Tabela 2. Produtos que podem ser obtidos por fermentação em estado sólido a partir de diferentes rejeitos

\begin{tabular}{lll}
\hline Produtos & Micro-organismos principais & Rejeitos usados como substratos \\
\hline Enzimas & & \\
Pectinases & Lentinus edodes & Resíduos de frutas \\
& Aspergillus carbonarius & Farelo de trigo \\
& Aspergillus niger & Polpa de café \\
Hemicelulases & Trichoderma longibrachiatum & Farelo de trigo \\
& Aspergillus tamarii & Farelo de trigo / Sabugo de milho / Bagaço de cana \\
Celulases & Trichoderma reesei & Palha de trigo \\
Amilases & Aspergillus niger & Farelo de trigo \\
& Aspergillus niger & Resíduos de chá \\
Protease & Rhizopus oryzae & Farelo de trigo \\
Lípases & Penicillium restrictum & Torta de babaçu \\
Fitase & Aspergillus niger & Farelo de trigo / Farinha de soja \\
Tanase & Aspergillus niger & Farelo de trigo \\
\hline
\end{tabular}

Substâncias orgânicas

Ácido cítrico

\begin{tabular}{ll} 
Aspergillus niger & Resíduo de maçã \\
Aspergillus niger & Bagaço de cana \\
Aspergillus niger & Resíduos de goiaba \\
Aspergillus niger & Resíduos de abacaxi \\
Gibberella fujikoroi & Farelo de trigo \\
Penicillium sp. & Sabugo de milho \\
\hline
\end{tabular}

Ácido giberélico 
de caracterização dos insumos utilizados como matérias-primas, bem como dos produtos obtidos.

É possível classificar as técnicas utilizadas como métodos de caracterização física ou de análise química, de acordo com o tipo de informação que fornecem. São extremamente importantes os métodos normatizados, aceitos por consenso entre as partes interessadas, como padrões pela legislação de diferentes países ou por acordos internacionais. ${ }^{58,59}$ Os métodos normatizados usam, sempre que possível, técnicas experimentais acessíveis e de baixo custo, e o seu uso é sempre recomendado, ao se elaborar as folhas de dados (data sheets, material safety and data sheets - MSDS) de qualquer matéria-prima ou produto. Entretanto, muitas vezes é necessário recorrer ao estado da arte na metodologia analítica e físico-química para se resolver novos problemas analíticos e de caracterização. A Tabela 3 apresenta uma relação de técnicas sofisticadas mas crescentemente usadas na pesquisa de matérias-primas e produtos delas derivados bem como à pesquisa de materiais. É muito comum que se utilize duas ou mais dessas técnicas, em um mesmo trabalho de caracterização e análise, pois as diferentes técnicas fornecem dados complementares. Para exemplificar esse aspecto, será descrito o papel de algumas delas no contexto dos insumos abordados nesse artigo e de produtos respectivos.

Por exemplo, no caso de argilas e dos materiais obtidos a partir das mesmas, como vidros especiais e cerâmicas supercondutoras, são realizadas análises por fluorescência de Raios-X (XRF), difração de Raios-X (XRD), métodos térmicos (DTA, DSC, DMA) e microscopias. As duas primeiras técnicas informam sobre a composição química e mineral; enquanto as técnicas de DTA e de DSC fornecem informações sobre o grau de hidratação e transformações de fases.

Várias técnicas encontram utilidade em sistemas muito diferentes. A microscopia eletrônica de varredura e a difração de Raios-X, hoje bastante disseminadas, são usadas em diferentes tipos de sólidos, informando sobre seu grau de cristalinidade, a estrutura cristalina e morfologia de partículas e fibras, inclusive sobre a dos seus domínios micrométricos e nanométricos.

No caso dos óleos vegetais que são usados nas indústrias de alimentos, cosméticos, tensoativos e polímeros, as análises usadas são um pouco diferentes. Emprega-se um conjunto de ensaios físico-químicos para determinar: umidade e material volátil, teores de lipídeos, de ácidos graxos livres e de peróxidos, índices de refração, de iodo e de saponificação, impurezas insolúveis em éter de petróleo, estabilidade oxidativa, ponto de fumaça e parâmetros sensoriais (aspecto, cor, odor e sabor). ${ }^{60,61}$ Além disso, também se pode empregar técnicas cromatográficas e/ou de espectrometria de massas, que possibilitam identificar as moléculas que compõem o óleo ${ }^{626364}$ e substâncias contaminantes ${ }^{65,66}$ principalmente pesticidas. A avaliação de óleos como matéria-prima é, portanto, uma tarefa bastante sistemática e demorada.

Muitas vezes se encontra referências a uma "análise completa" de algum produto, mas não existe nada que se aproxime desse conceito.
O trabalho de caracterização é quase sempre complexo e demorado, pois para cada tipo de insumo/material exige um preparo de amostra específico, bem como técnicas analíticas mais adequadas.

Consequentemente, o estudo de insumos naturais produzindo um conhecimento prévio e objetivando futuras aplicações é ainda escasso. Mesmo as argilas e os óleos naturais, que são usados pelo setor produtivo em um grande número de aplicações e em grande escala, não são caracterizados e/ou mapeados o suficiente, ${ }^{67}$ para se poder prever o seu comportamento em novas e variadas situações.

A correlação entre as características de matérias-primas e propriedades dos respectivos materiais relevantes para sua aplicação é demonstrada no caso de argilas, em trabalho de Coelho et al. ${ }^{68} \mathrm{~A}$ cor branca e a baixa granulometria das partículas que constituem as argilas cauliníticas tornam-nas apropriadas para o uso na indústria de papel, cerâmica e plásticos brancos. Por outro lado, as argilas bentoníticas podem ser brancas ou não, dependendo da presença de alguns metais em sua composição. Quando predominam íons de Li, $\mathrm{Na}, \mathrm{K}$ e Ca as argilas são mais claras, enquanto $\mathrm{Fe}, \mathrm{Cr}$ e $\mathrm{Ni}$ conferem diferentes cores. Logo, para a obtenção de produtos onde a cor é indesejável, apenas alguns tipos podem ser usados.

Informações analíticas são importantes para compor bancos de dados sobre os recursos naturais brasileiros, como aqueles que estão sendo elaborados pelo IBGE para solos e vegetação. ${ }^{69} \mathrm{~A}$ consolidação de uma já apreciável quantidade de informação depositada em revistas, teses e publicações de congressos em bancos de dados acessíveis aos pesquisadores, empresários, planejadores e ao público em geral é cada vez mais necessária.

Outro aspecto importante, relacionado a um melhor aproveitamento dos recursos naturais, é a preservação do ambiente e a sustentabilidade das tecnologias, novas ou não. Neste cenário se enquadram os rejeitos industriais que, para terem uma disposição e/ ou aproveitamento adequados, precisam ser analisados e suas propriedades devem ser conhecidas. Por exemplo, um estudo de Borges et $a l .{ }^{70}$ mostrou que sementes de umbu, planta típica do semi-árido, é uma boa fonte de alguns minerais ( $\mathrm{P}, \mathrm{K}, \mathrm{Mg}, \mathrm{Fe}$ e $\mathrm{Cu}$ ). Essas sementes poderiam ser utilizadas pela indústria alimentícia como fonte adicional de minerais quando é necessário (ou desejável) enriquecer o valor nutricional de alimentos.

É necessário manter uma contínua atividade de pesquisa para aperfeiçoar as técnicas e métodos existentes, além de criar novos métodos para necessidades novas ou que aproveitem novos desenvolvimentos científicos. A análise e caracterização de grandes quantidades de amostras exigem técnicas poderosas de screening e high-throughput screening (HTS), bem como o de técnicas adequadas aos ensaios de campo, que são úteis para caracterizar as matériasprimas in situ, no seu local de origem.

Técnicas de screening são técnicas de análise que possibilitam identificar, rapidamente, características específicas de um material. Uma técnica com essas características foi desenvolvida, recentemente,

Tabela 3. Técnicas analíticas necessárias ao estudo de matérias-primas e de produtos delas derivados

Técnicas de caracterização morfológica, térmica, mecânica, óptica, reológica e magnética

1- microscopias: eletrônica de varredura, de transmissão, de força atômica e óptica

2- métodos térmicos: DTA, DSC, TGA

3- ensaios mecânicos e dinâmico-mecânicos

4- ensaios reológicos, determinação de viscosidade

5- espalhamento em baixo ângulo de raios-X, luz e nêutrons

6- ressonância paramagnética eletrônica e determinação de magne-

tização
Técnicas de determinação de composição química

1- espectrometria de emissão óptica em plasma, ICP OES

2- espectrometria de massas com fonte de plasma, ICP-MS

3- espectroscopia: no infravermelho, no ultra-violeta e visível

4- difratometria de raios-X, XRD

5- fluorescência de raios-X, XRF e micro-análise por raios-X (EDS)

6- ressonância magnética nuclear, RMN 
pela Embrapa Instrumentação Agropecuária, em São Carlos, para medidas ultrarrápidas da quantidade e qualidade de óleos vegetais presentes em sementes que são candidatas ao uso na fabricação de biodiesel. ${ }^{71} \mathrm{~A}$ técnica baseia-se na ressonância magnética nuclear, apresenta uma elevada frequência analítica e, por não ser "destrutiva", isto é, não exige tratamento químico da amostra, também não gera resíduos, o que é uma vantagem ambiental do uso da mesma. Permite selecionar com rapidez as sementes com alta produtividade, de maneira que seria bastante estratégico tornar esse desenvolvimento disponível ao setor agroindustrial.

Em análises inorgânicas, as técnicas de $\mathrm{XRF}^{72}$ e espectrografia ${ }^{73}$ são bem consolidadas na análise dos elementos constituintes de uma amostra, podendo ser executados em equipamentos portáteis. Além dessas, uma outra possibilidade para a análise elementar, ainda menos usual no Brasil, é a técnica de LIBS (espectroscopia de emissão em plasma induzido por laser). Tem as mesmas aplicações que as duas anteriores e é muito semelhante à espectrografia, mas tem a vantagem de poder ser usada para amostras não-condutoras, como os sólidos vítreos e cerâmicos. ${ }^{74}$ Alguns desenvolvimentos dessa técnica visam seu uso na análise da porção orgânica de amostras. Para isso existe a perspectiva de acoplá-la à espectroscopia Raman em um mesmo instrumento, criando uma nova ferramenta suficientemente poderosa para ser usada em screening.

Por outro lado, há muitas possibilidades de se estender as técnicas de XRF e espectrografia à caracterização de amostras muito complexas, combinando-as aos métodos quimiométricos. Alguns estudos nesta linha estão sendo feitos com o uso do espalhamento de raios-X, medido com a técnica de XRF e análise multivariada. Este recurso está possibilitando identificar espécies orgânicas em algumas matrizes, como óleos vegetais e álcoois..$^{75,76}$ Neste momento, as metodologias desenvolvidas se aplicam à classificação (ou diferenciação) de óleos vegetais comestíveis e de álcoois, visando monitorar adulterações em produtos industrializados desses materiais. Logo, conseguir quantificar as substâncias orgânicas e não apenas identificá-las é um desafio futuro para a técnica de XRF e de especial importância para a monitoração de substâncias tóxicas ${ }^{77}$ e poluentes em produtos agrícolas.

Em suma, a caracterização e análise de recursos minerais e vegetais está diretamente relacionada à produção química, de novos materiais, aproveitamento de rejeitos e sustentabilidade. O trabalho analítico se faz presente em todas as etapas do setor produtivo e tem sido focado na seleção de matérias-primas apropriadas para se obter produtos de boa qualidade. Entretanto, a otimização do aproveitamento dos recursos naturais como matérias-primas, requer pesquisas sistemáticas e abrangentes de caracterização e mapeamento de insumos, tal como ocorre com os óleos amazônicos, ${ }^{78}$ devido ao interesse da indústria de produtos de uso pessoal e cosméticos. Técnicas de screening devem ser difundidas e aprimoradas e os resultados obtidos devem ser não apenas divulgados através de publicações e congressos, mas também reunidos em bases de dados disponíveis a todos os interessados, mediante regras de acesso transparentes e justas para todas as partes.

\section{Sustentabilidade: a fixação de carbono e nitrogênio}

Qualquer discussão sobre a produção de matérias-primas de origem vegetal ou animal tem de incluir uma análise da sua sustentabilidade. Para isso, é necessário considerar os seus impactos sobre a qualidade do solo, dos reservatórios e mananciais de água, a fixação de carbono e o hidrogênio no solo bem como o suprimento e reposição de nutrientes $(\mathrm{N}, \mathrm{P}, \mathrm{K})$ e de um grande número de oligoelementos.

Solos da maior parte do território brasileiro, especialmente no Sudeste, Centro-Oeste e Norte são pobres em muitos componentes minerais. Isso é devido à idade dos terrenos e ao clima que prevalece há dezenas de milhares de anos, do qual as chuvas ácidas são uma componente importante. Têm ocorrido melhoras importantes na qualidade de solos brasileiros, especialmente no Cerrado, devido à redução da acidez pela calagem e à incorporação de matéria orgânica resultante do próprio cultivo e das práticas de plantio direto. A fixação de carbono nos solos tem um outro aspecto muito importante: ela é um objetivo da agenda de mitigação das mudanças climáticas globais, devido à grande capacidade de solos como reservatórios (sinks) de carbono. Além disso, ela tem ainda um efeito positivo na mobilização de potássio, fósforo e outros elementos encontrados em rochas, tornando-os mais disponíveis aos vegetais e, portanto, reduzindo a necessidade de uso de fertilizantes.

A fixação do nitrogênio também é beneficiada pelo aumento no teor de matéria orgânica no solo. Por outro lado, é uma importante estratégia de sustentabilidade porque permite uma redução nos grandes gastos de energia e de hidrogênio com o processo Haber-Bosch.

O Brasil tem um sucesso econômico e ambiental muito importante na fixação de nitrogênio a solos, no caso da soja. As sementes de soja brasileira são inoculadas com micro-organismos fixadores, o que produz uma importante redução no consumo de fertilizantes nitrogenados e cria uma vantagem para os custos de produção da soja brasileira, se comparada à norte-americana.

A fixação de carbono e nitrogênio aos solos é conseguida utilizando-se boas práticas agrícolas. Portanto, é um objetivo que interessa à sustentabilidade tanto quanto à economicidade da produção de matérias-primas vegetais e animais.

\section{O caso do enxofre: múltiplas conexões}

O caso do enxofre merece ser discutido, como um exemplo das múltiplas conexões entre a produção de materiais e energia, bem como das suas relações com o aproveitamento de resíduos industriais.

O enxofre é a matéria-prima menos abundante, entre as que são usadas na produção de ácido sulfúrico, que por sua vez é o produto que a indústria química fabrica em maior volume, em todo o mundo. Os Estados Unidos produzem cerca de 50\% do total global e os outros maiores produtores são todos países muito desenvolvidos. Este ácido é largamente usado em um sem-número de indústrias, fazendo parte de qualquer cadeia produtiva hoje existente no mundo, em maior ou menor escala.

O Brasil não tem depósitos de enxofre de qualidade adequada ao processo catalítico atual e o enxofre disponível internamente, até os anos 60, era o contido na pirita existente no carvão brasileiro. Nos anos 60 teve início, no Brasil, o aproveitamento do enxofre existente no petróleo, onde ele é altamente indesejável devido ao seu papel poluente em atmosferas urbanas. Hoje, as unidades industriais que queimam enxofre para fazer ácido sulfúrico são também cogeradoras de energia, devido ao seu elevado calor de combustão.

Em um cenário de carência de petróleo, surgirá também a necessidade de se recorrer a outras fontes de enxofre. Portanto, é preciso aproveitar as possibilidades de produção de enxofre a partir de matérias-primas vegetais ou de resíduos industriais e agrícolas, além de dejetos. Essa possibilidade existe, principalmente na forma de gás sulfídrico e de mercaptanas, que são gases produzidos em qualquer processo de fermentação anaeróbica. De fato, biodigestores de todos os tipos produzem estes gases, extremamente malcheirosos e que devem ser sempre removidos por lavagem antes do uso.

Portanto, a desulfurização de gases produzidos em fermentação anaeróbica de resíduos industriais, agrícolas ou municipais é uma possível fonte de enxofre, tal como é hoje a desulfurização do petróleo. Dentro de um conceito de biorrefinarias, esta pode vir a ser uma fonte renovável de enxofre e (como ocorre atualmente) de energia contribuindo, assim, para a disponibilidade de ácido sulfúrico. 
Essa questão deve ainda ser vista de um outro ângulo. O ácido sulfúrico, produzido em enormes quantidades, está explicitamente presente em muitos poucos produtos acabados. Portanto, ele é um intermediário que termina seu ciclo de vida na forma de sulfatos, em depósitos de resíduos ou em efluentes de vários tipos. Entretanto, a redução desses sulfatos, por métodos fermentativos ou por reação com materiais carbonosos, deve permitir a reciclagem do enxofre através da formação inicial de sulfetos ou mercaptanas, seguida da sua transformação em enxofre puro.

Finalmente, vale a pena registrar o que tem ocorrido com os preços do enxofre, no conturbado período que teve início no segundo semestre de 2007, estendeu-se por 2008 e cuja evolução é, neste momento, imprevisível. O preço da tonelada de enxofre, em meados de 2007, era de ordem de 60-70 US\$/tonelada, decrescente. Ocorreu então um rápido aumento, chegando-se a cerca de US\$700 em junho de 2008. Logo em seguida a setembro de 2008 o preço caiu bruscamente, chegando no início de 2009 até a US\$40. Esse é um exemplo dramático das incertezas pelas quais passamos, em fevereiro de 2009.

\section{PROPOSTAS}

As diferentes fontes de matérias-primas renováveis e abundantes apresentam-se em diferentes estágios de aproveitamento, de conhecimento e de desenvolvimento científico e tecnológico. O seu tratamento deverá ser feito através de diferentes estratégias, que estão resumidas a seguir:

1. Levantamento de fontes de matérias-primas para materiais.

2. Caracterização de matérias-primas potenciais de materiais, de origem natural.

3. Desenvolvimento de materiais obtidos de fontes renováveis ou de reciclagem de materiais e dos respectivos processos.

4. Investigação inicial de produtos e processos inovadores, que hoje não façam parte do estado da arte de aproveitamento de matériasprimas naturais.

\section{Levantamento de fontes de matérias-primas para materiais}

Neste caso, é preciso inicialmente reconhecer o pouco conhecimento das características geológicas do território nacional, com o grau de detalhe necessário para a produção de matérias-primas para materiais avançados. Um exemplo é o das mudanças recentes no cenário da produção cerâmica para a construção civil, no território nacional. O estado de São Paulo assumiu, nas últimas duas décadas, uma posição de grande destaque devido à constatação da existência de grandes depósitos de materiais argilosos que, com uma mínima preparação, se prestam à produção de cerâmica vermelha e branca de muito boa qualidade. Não se trata de uma descoberta revolucionária, nem do ponto de vista geológico, nem do ponto de vista tecnológico. Certamente, não há nada neste trabalho que justifique patentes importantes ou publicações de alto fator de impacto. Nem mesmo houve noticiário na imprensa, que valorizasse o fato. Entretanto, ele é óbvio para quem observa o brotamento intensivo de novas indústrias cerâmicas na região de Santa Gertrudes e Cordeirópolis, em uma região do estado que já era intensamente ocupada na segunda metade do século XIX. A importância desta atividade econômica baseada em um recurso natural muito abundante e quase trivial só adquiriu notoriedade nacional no recente episódio de ameaça de suprimento de gás natural, quando as cerâmicas paulistas apareceram entre os maiores consumidores de gás do país. Portanto, é essencial que seja feito um trabalho contínuo e sistemático de conhecimento do território e de detecção de realidades minerais que hoje jazem desconhecidas ou subaproveitadas. Esse trabalho poderia beneficiar-se imensamente de uma atividade investigativa realizada por professores de escola fundamental e secundária, engenheiros e trabalhadores de prefeituras, agrônomos e técnicos extensionistas e mais os portadores de saberes tradicionais, que podem deter informações preciosas, desde que sejam colocadas em um contexto apropriado.

$\mathrm{O}$ caso de matérias-primas vegetais está ligado às questões da biodiversidade, de um lado, e ao conhecimento das cadeias de produção vegetal e animal, de outro. Neste caso, a iniciativa privada mostra às vezes um grande dinamismo e capacidade inovativa. Por outro lado, observa-se também uma dicotomia entre as atividades privadas, de governo e de pesquisadores mantidos pelo governo. Por exemplo, ramnose é um açúcar que tem aspectos muito atraentes na produção de tensoativos, que por sua vez são essenciais à produção de muitos materiais poliméricos. A principal fonte de ramnose, ${ }^{79}$ no mundo, é uma empresa brasileira, a PVP S/A, que opera no Piauí. Na Plataforma Lattes, uma busca feita sobre esta palavra chave mostra a existência de pelo menos oito grupos de pesquisa atuando na área. Entretanto, não foi possível detectar nenhuma conexão entre os grupos que aparecem na plataforma Lattes e a empresa PVP.

Caracterização de matérias-primas potenciais de materiais, de origem natural

Este tipo de trabalho tem pontos em comum com o anterior, mas trata mais de identificar, com o suficiente detalhe, características especiais de materiais comuns, agregadoras de valor. Para ilustrar as situações que podem ocorrer, são apresentados a seguir dois casos.

O primeiro foi relatado a um dos autores em 1995 e ocorreu em uma empresa de mineração, cujo pessoal percebeu que uma certa jazida de calcáreo tinha um teor de sílica muito baixo. Esta jazida se situa no estado do Mato Grosso do Sul. O teor reduzido de sílica confere ao carbonato de cálcio extraído dessa jazida uma abrasividade muito baixa, que é muito apreciada pelas empresas fabricantes de papel, pois ela implica em um menor desgaste de partes componentes das grandes e caras máquinas usadas na produção de papel. Em consequência, o carbonato de cálcio, simplesmente extraído, moído e classificado consegue um sobrepreço muito significativo. Outros exemplos desse tipo são conhecidos de todas as pessoas que têm alguma relação com a produção mineral ou com o uso de produtos minerais.

O segundo refere-se ao uso de celulose para a produção de fibras semissintéticas de celulose, que surgiram no mercado consumidor na década de 1980. Este processo, então revolucionário, é baseado na dissolução de celulose em dimetilformamida na presença de cloreto de lítio, seguida da sua fiação em banhos coagulantes. Portanto, depende criticamente da solubilidade completa da celulose utilizada. A empresa que introduziu o produto inicialmente, a Courtaulds, utilizou como fonte de celulose uma espécie única, não-tradicional na produção de celulose e plantada em uma região definida nos Estados Unidos. As razões dessa alta especificidade não foram divulgadas em detalhe, mas se pode supor que esteja ligada às características químicas, micro e nano-estruturais da celulose desta fonte específica, que lhe confiram uma vantagem importante sobre celuloses amplamente usadas, por exemplo, pela indústria de papel.

Este trabalho de caracterização minuciosa está estreitamente vinculado às necessidades de uso de cada produto e principalmente dos processos em que ele será utilizado. Portanto, trata-se de características que o produtor da matéria-prima, isoladamente, nunca pode perceber. Isso depende muito de trabalho em equipe e também de um comportamento ético por parte de cada pessoa envolvida, para que seja mantido o necessário sigilo. Aplicações novas exigem dados mais específicos do que os requeridos pelos ensaios de determinação de conformidade usuais, necessariamente relevantes para os novos usos e criando novas especificações. 
Desenvolvimento de materiais obtidos de fontes renováveis ou de reciclagem de materiais e dos respectivos processos

A justificativa para este tipo de trabalho é o grande número de possibilidades abertas pelas novas tecnologias para a criação de novos materiais avançados, a partir de substâncias químicas e matériasprimas bem conhecidas. O melhor exemplo é o dos nanocompósitos de polímero e argila, ${ }^{80,81}$ no qual commodities já bem conhecidas e exploradas são combinadas formando produtos revolucionários, com propriedades até aqui inexistentes em quaisquer materiais. Esse tipo de trabalho tem um atrativo muito grande, quanto à segurança toxicológica e ambiental dos produtos gerados por ele: não requer a introdução precipitada de componentes e substâncias novas, que tragam riscos devido à própria falta de informação sobre as suas propriedades.

Podemos comparar os nanocompósitos de polímeros e argilas com os nanocompósitos de polímeros e nanotubos de carbono: no primeiro caso, são usadas substâncias bem conhecidas. As argilas, em especial, são familiares à espécie humana há milênios fazendo parte do convívio de bilhões de pessoas. Portanto, há pouco a temer, do ponto de vista de segurança no uso destes materiais. Já o mesmo não pode ser dito dos nanotubos de carbono e mesmo de outras nanopartículas obtidas recentemente, cujos efeitos sobre seres humanos e ecossistemas são, na melhor das hipóteses, pouco conhecidos.

A reciclagem oferece um grande número de oportunidades econômicas e é uma exigência de qualquer sistema que se pretenda sustentável. Observando-se o tratamento dado aos resíduos municipais e industriais, no Brasil, torna-se óbvio que as possibilidades da reciclagem são amplamente ignoradas, ainda hoje.

Por isso mesmo, é preciso lembrar alguns fatos importantes:

1) O uso de latas de alumínio para armazenar bebidas seria completamente inviável, se dependesse apenas de alumínio virgem. O uso do alumínio reciclado, que consome muito menos energia do que a produção do alumínio virgem, torna essa tecnologia economicamente viável e cria oportunidades econômicas para muitas pessoas cujas oportunidades de renda são muito piores do que o trabalho de coleta de latas.

2) O PET, também usado em embalagens de bebidas e frequentemente apontado como causador de poluição ambiental, pode ser reciclado gerando resultados econômicos importantes. Durante muitos anos (e talvez até o momento presente) a maior recicladora de PET do Brasil, situada na cidade de Jundiaí, pertencia à mesma empresa que é a maior produtora de PET nesse país. Isso revela um fato simples: o produtor de um material, tendo controle do mercado ou de parte dele, tem como aproveitar o material o seu produto em diferentes estágios do seu ciclo de vida e em diferentes formas, encontrando para o material reciclado nichos de mercado compatíveis com as suas características.

Investigação inicial de produtos e processos inovadores, que hoje não façam parte do estado da arte de aproveitamento de matérias-primas naturais

Os exemplos utilizados para ilustrar esse tipo de atividade são dois: o dos pigmentos brancos à base de fosfato de alumínio ${ }^{82}$ e o dos nanocompósitos de látex e argilas hidrofílicas, ${ }^{83}$ que foram desenvolvidos no laboratório dos autores desse estudo.

Relatos detalhados sobre os pigmentos de fosfato de alumínio foram publicados recentemente ${ }^{84} \mathrm{e}$ não serão repetidos aqui. Esse desenvolvimento dependeu fortemente de duas idéias:

1) Sólidos inorgânicos amorfos são uma classe negligenciada de substâncias químicas, ainda pouco conhecidas apesar da sua aparente simplicidade. Certamente poderão ainda ser exploradas na criação de muitos produtos, em muitos casos paralelos aos dos desenvolvimentos observados com sílicas amorfas e processos sol-gel.

2) Um material pode valer muito mais pelas funções que pode exercer do que pelas suas propriedades intrínsecas. Excetuando-se uns poucos casos excepcionais como, por exemplo, o do ouro e outros metais preciosos, é sempre possível substituir um material por outro desde que seja atingido o mesmo conjunto de propriedades necessário ao seu uso. O fosfato de alumínio, se depender apenas de suas propriedades intrínsecas, não pode competir com o óxido de titânio, como pigmento. Entretanto, o fosfato de alumínio nanoestruturado tem excelentes propriedades de pigmentação.

Já no caso dos nanocompósitos de látex e argila, a idéia central se baseou nas experiências deste grupo de pesquisa no estudo de látexes e de nanocompósitos, separadamente. Estas permitiram que o grupo adotasse um caminho divergente daquele mais frequente na literatura científica e de patentes, mas que se mostrou fértil dos pontos de vista científico e econômico.

Cientificamente, os resultados obtidos mostraram a importância das ligações eletrostáticas na nanoestruturação de materiais, até aqui praticamente negligenciada e que foi objeto de recente publicação. ${ }^{85}$ Essa possibilidade muda paradigmas da formação de compósitos, nanocompósitos e blendas, criando muitas novas possibilidades de criação de novos materiais.

\section{CONCLUSÕES}

A intensificação na produção de biomassa é uma exigência dos esforços de mitigação dos efeitos da mudança do clima, uma vez que não existe outra alternativa viável a curto prazo para a fixação de grandes quantidades de gás carbônico. Por outro lado, essa produção gera alimentos, combustíveis sólidos e líquidos e matérias-primas para a indústria química e de materiais, podendo ser acompanhada da exploração de matérias-primas minerais que, embora não renováveis, sejam abundantes e de baixo consumo energético. O aproveitamento destes tipos de matérias-primas pela indústria deverá beneficiar-se de desenvolvimentos importantes nas nanotecnologias, biotecnologias, tecnologias da informação e de microrreatores, gerando produtos novos, que preencham funções desejáveis e necessárias, fabricados por processos brandos e que impulsionem o desenvolvimento econômico e social, em padrões duráveis e, sempre que possível, sustentáveis.

\section{REFERÊNCIAS}

1. Galembeck, F.; Anais do Simpósio da Academia Brasileira de Ciências, São Paulo, Brasil, 1997.

2. Lipinsky, E. S.; Science 1978, 199, 644.

3. http://lqes.iqm.unicamp.br/canal_cientifico/lqes_news/lqes_news_cit/ lqes_news_2006/lqes_news_novidades_810.html, acessada em Outubro 2007.

4. Zhao, Q. Q.; Boxman, A; Chowdhry U.; J. Nanopart. Res. 2003, 5, 567.

5. http://www.chemicalvision2020.org, acessada em Março 2009.

6. http://www.chemicalvision2020.org/nanotechnology.html, acessada em Março 2009.

7. http://www.mct.gov.br/upd_blob/0007/7608.pdf, acessada em Março 2009.

8. Rosseto, R.; Santos, A. C. M.; Galembeck, F.; J. Braz. Chem. Soc. 2006, $17,1465$.

9. http://www.lisina.com.br/noticias_detalhes.aspx ?id=292, acessada em Março 2009.

10. http://news.bbc.co.uk/1/hi/sci/tech/889951.stm, acessada em Março 2009. 
11. Galembeck, F.; 1st Brazilian Workshop on Green Chemistry, Fortaleza, Brasil, 2007.

12. http://www.iupac.org/publications/pac/2002/pdf/7412x2271.pdf, acessada em Março 2009.

13. http://www.aist.go.jp/aist_e/latest_research/2006/20060220/20060220 html, acessada em Março 2009.

14. http://www.lonza.com/group/en/company/news/publications_of_lonza.ParSys-0002-ParSysdownloadlist-0001-DownloadFile.pdf/1_050510_ Microreactor Technology Revolution for the Fine Chemical and Pharmaceutical Industries.pdf, acessada em Março 2009.

15. http://www.bhrgroup.co.uk/confsite/pi05home.htm, acessada em Março 2009.

16. http://www.lionixbv.nl/download/html/Siemens Webzine PoF 02_02Lilliputian Factories.htm, acessada em Março 2009.

17. http://www.tno.nl/content.cfm? \&context=markten $\&$ content $=$ case $\&$ laag1=190\&item_id=268\&Taal=2, acessada em Outubro 2007.

18. http://www.llnl.gov/pao/news/news_releases/2005/NR-05-08-04.html, acessada em Março 2009.

19. Falabella, E.; comunicação pessoal.

20. http://books.google.com/books?id=pIIwAAAAMAAJ\&dq=United+ Nations+publication.+Sales+no.:+ E.69.II.B.39,+vol.+9.\&pgis $=1$, acessada em Março 2009.

21. http://www.sciam.com/blog/60-second-science/post.cfm?id=germanchemist-gets-15-million-birt, acessada em Março 2009.

22. Storck, W.; Chem. Eng. News 2006, 84, 29.

23. http://www.jornaldaciencia.org.br/Detalhe.jsp?id=61905, acessada em Março 2009.

24. http://www.plasticstrends.net/index.php?option=com_content\&task= view\&id=41\&Itemid=40, acesso em Outubro 2007.

25. Tullo, A.; Chem. Eng. News 2005, 83, 11.

26. http://www.mct.gov.br/index.php/content/view/66226.html, acessada em Novembro 2007.

27. Ferber, E.; Cimarron, Grosset \& Dunlap: New York, 1929.

28. http://www.riosvivos.org.br/canal.php?canal=34\&mat_id=4982, acessada em Fevereiro 2009.

29. http://www.usp.br/agenciausp/bols/1998_2001/rede849.htm, acessada em Fevereiro 2009.

30. http://www.abiquim.org.br/pdfs/ele_50_impexp_2006.pdf, acessada em Novembro 2007.

31. http://www.ibs.org.br/publicacoes.asp, acessada em Novembro 2007.

32. http://www.revistapesquisa.fapesp.br/index.php?art $=1650 \& b d=$ $1 \& p g=1 \& \lg =$, acessada em Novembro 2007.

33. http://www.abal.org.br/industria/estatisticas_recicla_total.asp?canal=8, acessada em Novembro 2007.

34. http://www.abal.org.br/servicos/biblioteca/futuras_geracoes_2000.asp, acessada em Novembro 2007.

35. Li, L. Y.; Waste Manage. 2001, 21, 525.

36. Silva, F. E. B.; Alves, M. C. M.; Motta, M.; Rev. Mat. 2007, 12, 322 .

37. Kumar, S.; Kumar, R.; Bandopadhyay, A.; Resour. Conserv. Recycl. 2006, $48,314$.

38. http://www.alcoa.com/global/en/about_alcoa/sustainability/pdfs/ sustain_highlights06.pdf, acessada em Novembro 2007.

39. http://www.eaa.net/upl/4/default/doc/SDI_brochure_nov06.pdf, acessada em Março 2009.

40. http://www.alcoa.com/australia/en/news/releases/20070429_ carboncapture.asp, acessada em Novembro 2007.

41. Cortez, L. A. B.; Lora, E. S.; Biomassa para Energia, Unicamp: Campinas, 2007.

42. Ezequiel, J. M. B.; R. Bras. Zootec. 2006, 35, 2050.

43. http://www.biodiesel.gov.br/, acessada em Novembro 2007.

44. http://invertia.terra.com.br/carbono/interna/0,,OI1690686-EI8935,00. html, acessada em Novembro 2007.
45. http://www.editorasoleil.com.br/revista/edicao_140_Biodiesel.html, acessada em Março 2009.

46. http://www.biodieselbr.com/noticias/biodiesel/bertin-constroi-usinabiodiesel-lins-12-08-06.htm, acessada em Novembro 2007.

47. http://agenciact.mct.gov.br/index.php/content/view/43160.html, acessada em Novembro 2007.

48. http://www.abiove.com.br/cotacoes_br.html, acessada em Novembro 2007.

49. Cerri, C.; Workshop on Physics and Chemistry of Climate Change and Entrepreneurship, São Paulo, Brasil, 2009.

50. Laufenberg, G.; Kunz, B.; Nystroem, M.; Bioresour. Technol. 2003, 87, 167.

51. Pelizer, L. H.; Pontieri, M. H.; Moraes, I. O.; J. Technol. Manage. Innov. 2007, 2, 118.

52. http://en.wikipedia.org/wiki/Industrial_fermentation, acessada em Novembro 2007.

53. www.cnpat.embrapa.br/home/down/index.php?pub/cot_102.pdf, acessada em Novembro 2007.

54. Pandey, A.; Curr. Sci. 1999, 77, 149.

55. Suryanarayan, S.; Biochem. Eng. J. 2003, 13, 189.

56. Holker, U.; Lenz, J.; Cur. Opin. Microbiol. 2005, 8, 301.

57. Durand, A.; Biochem. Eng. J. 2003, 13, 113.

58. http://www.abnt.org.br/, acessada em Março 2009.

59. http://www.astm.org/, acessada em Março 2009.

60. Kobori, C. N.; Jorge, N.; Ciênc. Agrotec. 2005, 29, 1008.

61. http://extranet.agricultura.gov.br/sislegis-consulta/servlet/Visualizar Anexo?id=12484, acessada em Outubro 2007.

62. Gramosa, N. V.; Silveira, E. R.; J. Essent. Oil Res. 2005, 17, 130.

63. Silva, A. C. M.; J. Essent. Oil Res. 2006, 18, 269.

64. Coutinho, D. F.; J. Essent. Oil Res. 2007, 19, 482.

65. Amvrazi, E. G.; Alcanis, T. A.; J. Agric. Food Chem. 2006, 54, 9642.

66. Frenich, A. G.; J. Agric. Food Chem. 2007, 55, 8346.

67. Menezes, R. R.; Neves, G. A.; Ferreira, H. C.; Cerâmica 2001, 47, 77.

68. Coelho, A. E.; Quim. Nova 2007, 30, 1282.

69. www.ibge.gov.br/home/geociencias/default_prod.shtm\#USO, acessada em Novembro 2007.

70. Borges, S. V. ; Quim. Nova 2007, 30, 49.

71. Vasconcelos, Y.; Pesquisa Fapesp 2007, 140, 70.

72. www.shimadzu.com.br/analitica/aplicacoes/espectrometros/raios-x/eds/ edx-aplic-2.aspx, acessada em Novembro 2007.

73. www.shimadzu.com.br/analitica/produtos/espectrometros/oes/pmimaster-sort.aspx, acessada em Novembro 2007.

74. Pasquini, C.; J. Braz. Chem. Soc. 2007, 18, 463.

75. Bortoleto, G. G.; Pataca, L. C. M.; Bueno, M. I. M. S.; Anal. Chim. Acta 2005, 539, 283.

76. Bortoleto, G. G.; Borges, S. S. O.; Bueno, M. I. M. S.; Anal. Chim. Acta 2007, 595, 38.

77. www.cnpa.embrapa.br/publicacoes/2005/DOC134.pdf, acessada em Novembro 2007.

78. www.ufpa.br/beiradorio/arquivo/Beira23/noticias/noticia3.htm, acessada em Novembro 2007.

79. Rico, I.; comunicação pessoal.

80. Valadares L.; Leite, C. A. P.; Galembeck, F.; Polymer 2006, 47, 672.

81. Bragança, F. C.; Valadares, L. F.; Leite, C. A. P.; Galembeck, F.; Chem. Mater. 2007, 19, 3334.

82. Galembeck, F.; Brito, J., U. S. pat. 2,006,211,798, 2006

83. Rippel, M. M.; Valadares, L. F.; Murakami, M. M.; Galembeck, F. Br PIO.301.193-3, 2003.

84. Galembeck, F.; Silva, M. C. V. M.; Rosseto, R.; Quim. Nova 2007, 30, 745.

85. Valadares, L. F.; Linares, E. M.; Bragança, F. C.; Galembeck, F.; J. Phys. Chem. C 2008, 112, 8534. 